\section{Robustheit eines Messverfahrens}

C. Vidal ${ }^{1}$ und W.-R. Külpmann ${ }^{2}$

${ }^{1}$ Landeskriminalamt Niedersachsen, Dezernat 53 „Chemie“, Hannover, Deutschland

${ }^{2}$ Hannover, Deutschland

Englischer Begriff robustness of a measurement procedure

Definition Fähigkeiten einer Methode, den interessierenden Analyten zuverlässig zu bestimmen, auch wenn die Anforde- rungen an das Messverfahren insgesamt technisch einfach gehalten sind und es bei der Durchführung der Methode zu leichten Abweichungen kommt.

\section{Literatur}

Gaus W, Muche R (2013) Medizinische Statistik: Angewandte Biometrie für Ärzte und Gesundheitsberufe. Schattauer Verlag, Stuttgart, S 135 